\title{
Blast mitigation by water in a bag on a tunnel floor
}

\author{
Tomotaka Homae ${ }^{1, *}$, Yuta Sugiyama ${ }^{2}$, Kei Shimura ${ }^{3}$, Kunihiko Wakabayashi ${ }^{2}$, Tomoharu Matsumura ${ }^{2}$ \\ and Yoshio Nakayama ${ }^{4}$ \\ ${ }^{1}$ Department of Maritime Technology, National Institute of Technology, Toyama College, Toyama, Japan \\ ${ }^{2}$ Research Institute of Science for Safety and Sustainability, National Institute of Advanced Industrial Science and Technology, Tsukuba, \\ Japan \\ ${ }^{3}$ Department of Mechanical Engineering, Keio Univ, Yokohama, Japan. \\ ${ }^{4}$ Planning Headquarters, National Institute of Advanced Industrial Science and Technology, Tsukuba, Japan
}

\begin{abstract}
Mitigation of blast wave, caused by explosion of explosives, from a straight tube using water in a bag (water bag) was evaluated. The length of the tube was $330 \mathrm{~mm}$ and the cross-section area was $30 \times 30$ $\mathrm{mm}^{2}$. One end of the tube was closed. The water bag was placed on the floor or closed end wall of the tube near the explosive. The thickness of water was $3 \mathrm{~mm}$. A specially designed small detonator, which contains lead azide of $100 \mathrm{mg}$, was ignited near the closed end wall of the tube. The blast pressure outside the tube was measured and examined. The blast wave was remarkably mitigated by the water bag. Equivalent ratio analysis revealed that the glass beads absorbed $33 \%-45 \%$ of explosion energy.
\end{abstract}

\section{Introduction}

Magazine used for storing explosives is generally installed in mountainous areas away from urban areas. The land suitable for residential area is limited in Japan, as Japan consists of islands and the ratio of flatlands is small. Thus, land development for housing near magazines is often taken place. As a result, residential buildings are increasingly located near magazines. In fact, maintaining such structures at a safety distance is becoming increasingly difficult. A subsurface magazine has an explosive storage chamber, a horizontal passageway, and a vertical shaft for vent. It was proposed and legislated in Japan. Subsurface magazines were proposed to reduce the effects of blast waves, fragments, and ground shock and to maintain a safety distance easily when storing explosives underground. Therefore, blast pressure evaluation of the area around a subsurface magazine is important.

Blast pressure around a subsurface magazine has been described in several reports [1-4]. The authors also carried out the experiments to evaluate the blast pressure. In a series of the experiments, the authors found that small amount of water on the floor of its storage chamber mitigated the blast pressure remarkably [5]. The authors have been studied the mitigation mechanism by experiments $[6,7]$ and numerical simulation $[8,9]$. Our previous study [6] concluded that the high-speed camera images showed that the water in the chamber did not move apparently after the explosion, hence, the energy conversion from the blast wave to kinetic energy of water was not main origin of the mitigation. In addition, it was also concluded [7] that the water far from the explosive are not dominant for the blast-wave mitigation, because the blast pressure was not mitigated if the water was not put right under the explosive but put the other part of the chamber. The results conclude that the mitigation of blast wave by water is mainly caused by the interaction between the explosion and the water very near the explosion point. The numerical simulations $[8,9]$ of this system concluded that internal energy transfer from the blast wave to the water caused the mitigation. This result can apply to reduce the damage by explosion in closed places, such as subsurface magazines, underground magazines and tunnels.

The blast mitigation by little amount of water on the floor of the closed places shown above was obvious; however, it is not easy to apply this technique to actual subsurface magazines, underground magazines, and tunnels, as the magazines should keep away from humidity in general. Accordingly, the authors propose that water in a bag (hereinafter, water bag) can be placed on the floor/wall instead of a water pond. If the water bag is adopted, it is easier to maintain, while the blast wave cannot directly contact with or enter the water surface because of the bag. The behaviour should be different.

In this study, small-scale experiments for evaluating the mitigation effect by the water bag were carried out. The water bag was placed on the floor or closed end wall of the tube near the explosive. The mitigation effect of the water bag is discussed.

\footnotetext{
* Corresponding author: homae $(a$, nc-toyama.ac.jp
} 


\section{Experiment}

\subsection{Test Explosives}

A specially designed electric detonator with $100 \mathrm{mg}$ lead azide (Showa Kinzoku Kogyo Co. Ltd.) was used as a test explosive. $4 \mathrm{kV}$ was applied to initiate the detonator (test explosive) using a firing system (FS-43; Teledyne RISI, Inc.).

\subsection{Straight Tube Model}

A straight tube was adopted as a model in this study, because examination of interaction between explosion and water bag was focused on. Although a subsurface magazine is L shape, as mentioned above, this technique can also apply to underground magazines and tunnels. The schematic diagram of the tube is shown in Fig. 1. The tube was made of transparent PMMA, thickness of $10 \mathrm{~mm}$. A cross section of inside the tube was square, whose sides were $30 \mathrm{~mm}$. The length was $300 \mathrm{~mm}$. Considering the stress near the explosion point, the test explosive was placed inside a cap, made of aluminum alloy. The distance between the top of the test explosive and the bottom wall of the cap was set to be $10 \mathrm{~mm}$. The cap was connected with the PMMA tube described above. Then, total length of the tube was $330 \mathrm{~mm}$.

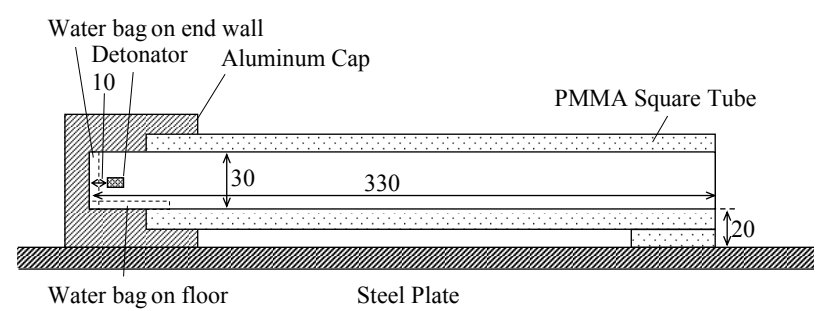

Fig. 1. Schematic diagram of the tube model used in this study.

\subsection{Ground Surface Model and Outside Pressure Measurement}

A steel plate, length of $3510 \mathrm{~mm}$, width of $2200 \mathrm{~mm}$, and thickness of $10 \mathrm{~mm}$, was regarded as a ground surface. As the steel plate is rigid compared with soil, the reflection of blast wave is large. Hence, the worst disaster can be estimated using this model. The tube was put on the steel plate and initiated. The height of the lower edge of the tube exit above the ground surface was $20 \mathrm{~mm}$ (See Fig. $1)$.

The blast pressure outside the tube was evaluated using four pressure transducers (113B28; PCB Piezotoronics, Inc.). The transducers were on an extended line of the centerline of the tube. The distances from the exit of the tube to the transducers were $200 \mathrm{~mm}, 600 \mathrm{~mm}$, $1000 \mathrm{~mm}$, and $1400 \mathrm{~mm}$, respectively. As the weight of the test explosive was $100 \mathrm{mg}$, corresponding Hopkinson scaled distance were from $4.3 \mathrm{~m} / \mathrm{kg}^{1 / 3}$ to $30.2 \mathrm{~m} / \mathrm{kg}^{1 / 3}$. This measurement was similar to that of the underground magazine or the earth-covered magazine model [10]. The pressure transducers were set with the vibration isolator
(GEL Tape; Taica Corp.). The transducer diaphragm was flush with the steel plate surface. The pressure measurement outside the model is precisely described elsewhere [7].

\subsection{Water Bag}

A small polyethylene bag was prepared. The thickness of polyethylene was $0.04 \mathrm{~mm}$. The placement of the water bag in the tube were varied for two ways. Firstly, the water bag was placed right under the explosive. Secondly, it was placed on the closed end wall (See Fig.1.). The size of the water bags depended on the way of placement. The water bag on the floor was $30 \mathrm{~mm} \times 50 \mathrm{~mm}$. The one on the closed end wall was $30 \mathrm{~mm} \times 30 \mathrm{~mm}$. Thickness of water layer was $3 \mathrm{~mm}$ in both cases. We presumed that the depth of water bag layer could be $10 \%$ of the inner side of a tunnel. The amount of the water was $4.5 \mathrm{~cm}^{3}$ and $2.7 \mathrm{~cm}^{3}$, respectively. The water bag for floor is shown in Fig. 2. The test explosive did not touch the water bag.

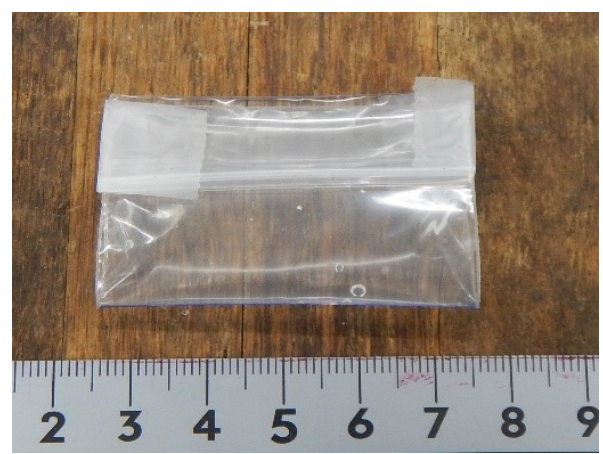

Fig. 2. Water bag for the floor.

\subsection{Number of Experiments}

The number of experiments are as follows. Without water bag was four times, the water bag on the floor (water bag on floor, hereinafter) was twice, and the water bag on the end wall (water bag on end wall, hereinafter) was once.

\section{Results and Discussions}

The obtained pressure histories were similar to those of surface explosion except for those at $200 \mathrm{~mm}$ from the tube exit. Consequently, blast parameters, such as peak overpressure and scaled impulse, were obtained and evaluated same as general blast waves caused by surface explosion. On the other hand, the pressure histories at 200 $\mathrm{mm}$ from the tube exit showed complex decay process because of the reflection of the blast wave in the tube. Then, comparison the data at $200 \mathrm{~mm}$ with the others was difficult. These data are omitted from the analysis, although these data are shown on the graphs.

The peak overpressure and the scaled impulse outside the tube were calculated from the pressure histories. The relation of those blast parameters and the scaled distance is shown in Figs. 3 and 4. The scaled distance is defined as the time integral of positive part of the pressure history divided by cubic root of explosive 
weight (100 mg in this study). The scaled distance is defined as the distance from the tube exit divided by cubic root of explosive weight.

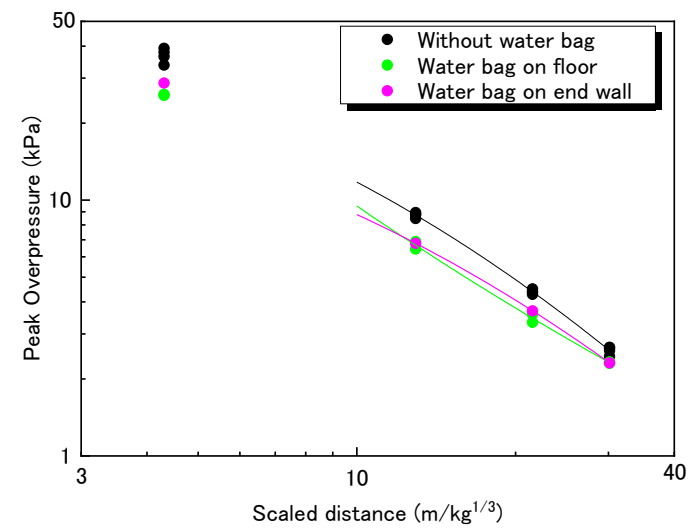

Fig. 3. Relation between the scaled distance and the peak overpressure outside the tube. The solid lines are the quadratic equation fitting for the data set obtained at the further three points for each experimental condition.

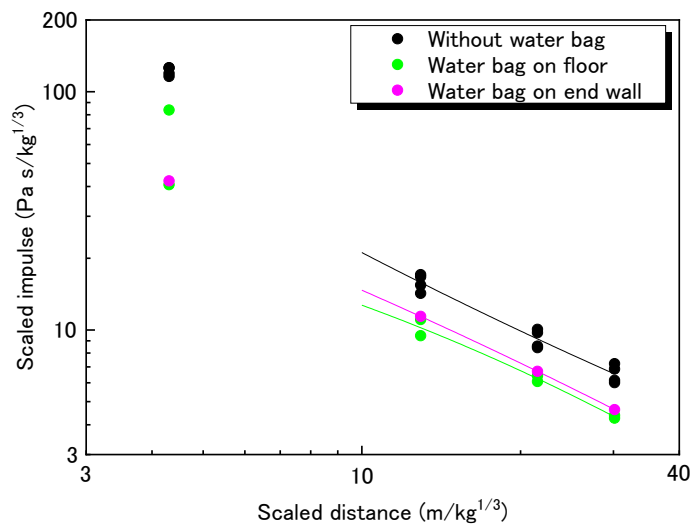

Fig. 4. Relation between the scaled distance and the scaled impulse outside the tube. The solid lines are the quadratic equation fitting for the data set obtained at the further three points for each experimental condition.

The peak overpressures and scaled impulses in the cases with water bags were mitigated. The results demonstrated the water bag mitigated the blast wave apparently.

Equivalent ratio was calculated to quantitatively evaluate the mitigation effect of the water bag. The equivalent ratio $r$ is defined as follows $[11,12]$

$$
r=\frac{W_{\text {without waterbag }}}{W_{\text {with waterbag }}}
$$

where $W_{\text {without waterbag }}$ is the weight of the explosive in explosion without water bag required to produce a selected blast wave parameter of equal magnitude to that produced by a weight of the explosive, $W_{\text {with waterbag, in }}$ each experimental condition with the water bag. If $r=1.0$, the weight of explosive was equal whether the water bag was placed or not. Namely, the water bag did not mitigate the blast wave at all. Small value of $r$ corresponds to the weak blast wave. Namely, the water bag mitigate the blast wave. In this study, the equivalent ratio was calculated using the peak overpressure $\left(r_{\mathrm{P}}\right)$ and the scaled positive impulse $\left(r_{\mathrm{I}}\right)$. The equivalent ratio also depends on the scaled distance. The method of calculation is described elsewhere [11].

In order to obtain the equivalent ratio, the relations between peak overpressure, scaled impulse, and scaled distance were fitted using quadratics on log-log plane. The solid lines in Figs. 3 and 4 represent the fitted curves. As the three data at the scaled distance from $12.9 \mathrm{~m} / \mathrm{kg}^{1 / 3}$ to were analysed in this study, the equivalent ratio from $10 \mathrm{~m} / \mathrm{kg}^{1 / 3}$ to $30 \mathrm{~m} / \mathrm{kg}^{1 / 3}$ was calculated. The average values in this range for each experimental condition were calculated for comparison [12]. The results are represented in Figs 5 and 6.

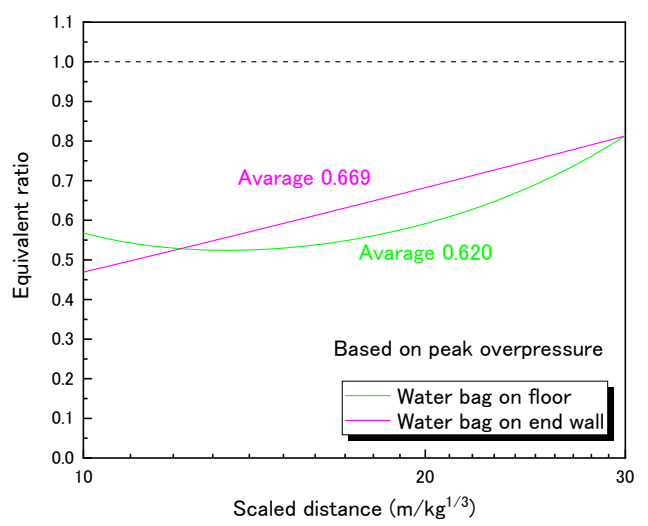

Fig. 5. Relation between equivalent ratio $r_{\mathrm{P}}$, based on peak overpressure, and scaled distance.

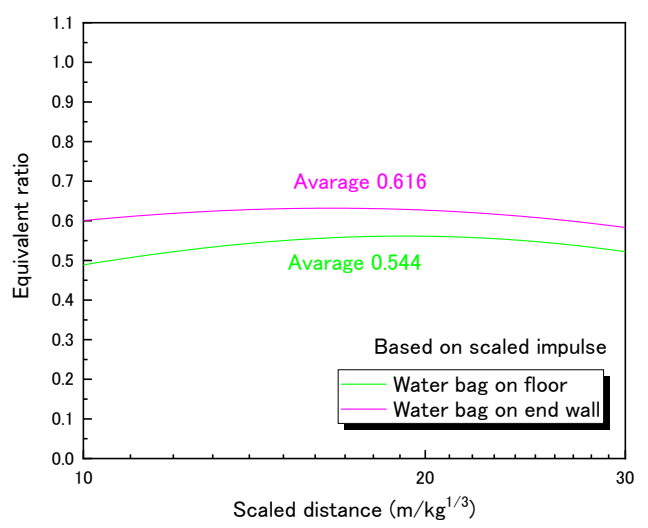

Fig. 6. Relation between equivalent ratio $r_{\mathrm{I}}$, based on scaled impulse, and scaled distance.

The equivalent ratio was small, when the water bag was placed on the floor. The average value was 0.625 (based on the peak overpressure) or 0.549 (based on the scaled impulse). This result indicates that the explosive 
amount of only approximately $60 \%$ can generate the same blast parameter if the water bag is not placed. Namely, approximately $40 \%$ of explosion energy was absorbed by the water bag. The mitigation effect was smaller when the water bag placed on the end wall. However, note that the total amount of water is different. The dependencies of equivalent ratio, based on peak overpressure, on scaled distance are different in Fig. 5. It may be caused by the scatter of the data of the peak overpressure. The dependencies should be examined in next subject.

The results demonstrated that the peak overpressure was mitigated for 33-45 \% by the water bag. Even though the blast wave did not contact with the water surface directly, the blast pressure was obviously mitigated. Energy transfer from blast wave to water by shock compression of water may be the origin of mitigation.

This new information can extensively apply to the explosion in closed places, such as subsurface magazines, underground magazines, and tunnel, for mitigation of blast wave.

This work was supported by JSPS KAKENHI Grant Number JP26350461.

\section{References}

1. T. Adachi,K. Munemasa, K. Hasue, and S. Nakahara, Propellants, Explosives Pyrotechnics, 16, 1-5 (1991)

2. H. Ichino, T. Ohno, K. Hasue, S. Date, Sci. Tech. Energetic Materials, 70, 38-42 (2009) (in Japanese)

3. H. Ichino, T. Ohno, K. Hasue, S. Date, Sci. Tech. Energetic Materials, 71, 51-57 (2010) (in Japanese)

4. Y. Nakayama, K. Wakabayashi, T. Matsumura, M. Iida, Applied Mechanics and Materials, 82, 663-668 (2011)

5. T. Homae, Y. Sugiyama, K. Wakabayashi, T. Matsumura, Y. Nakayama, Sci. Tech. Energetic Materials, 77, 18-21 (2016).

6. T. Homae, Y. Sugiyama, K. Wakabayashi, T. Matsumura, Y. Nakayama, Proc. of SPIE, 10328, 10328 1D-1-1D-6 (2017)

7. T. Homae, Y. Sugiyama, K. Wakabayashi, T. Matsumura, Y. Nakayama, Materials Science Forum, 910, 149-154 (2018)

8. Y. Sugiyama, T. Homae, K. Wakabayashi, T. Matsumura, Y. Nakayama, Materials Science Forum, 910, 78-83 (2018)

9. Y. Sugiyama, T. Homae, K. Wakabayashi, T. Matsumura, Y, Nakayama, Int. J. Multiphase Flow, 99, 467-473 (2018)

10. D. Kim, T. Matsumura, Y. Nakayama, Sci. Tech. Energetic Materials, 74, 100-105 (2013)

11. E.D. Esparza, Int. J. Impact Engng., 4, 23 (1986)

12. M.M. Swisdak, Jr., Explosion Effects and Properties Part I - Explosion Effects in Air, NSWC/WOL/TR 75-116 (1975) 